\title{
Association of Urban Liveability with Cancer Incidence in Iran: A Nationwide Ecological Study
}

\author{
Zahra Khorrami ${ }^{1}$, Moghadameh Mirzai ${ }^{2}$, Mohammad Mehdi Fadakar Davarani ${ }^{3}$ and Narges Khanjani \\ (iD) $4,{ }^{*}$ \\ ${ }^{1}$ Ophthalmic Research Center, Research Institute for Ophthalmology and Vision Science, Shahid Beheshti University of Medical Sciences, Tehran, Iran \\ ${ }^{2}$ Modeling in Health Research Center, Institute for Futures Studies in Health, Kerman University of Medical Sciences, Kerman, Iran \\ ${ }^{3}$ Department of Health Education and Promotion, School of Health, Kerman University of Medical Sciences, Kerman, Iran \\ ${ }^{4}$ Neurology Research Center, Kerman University of Medical Sciences, Kerman, Iran \\ "Corresponding author: Neurology Research Center, Kerman University of Medical Sciences, Kerman, Iran. Email: n_khanjani@kmu.ac.ir
}

Received 2020 October 19; Revised 2021 August 01; Accepted 2021 August 01.

\begin{abstract}
Background: Urban liveability is a multidimensional concept associated with many domains of human health. Objectives: This study aimed at investigating the association between urban liveability and cancer incidence in Iran.

Methods: The data of provincial-level urban liveability were obtained from reliable sources. The data of cancer incidence were inquired from the population-based cancer registry of the Iranian Ministry of Health and Medical Education in 2016. Urban liveability scores were determined in all provinces of Iran by utilizing the Global Liveable City Index (GLCI) method. Negative binomial Poisson regression was used to examine the relationship between urban liveability and cancer incidence.

Results: Provinces with a higher urban liveability had a higher likelihood of cancer incidence. Higher economic score was significantly associated with higher incidence in colorectal ( $I R R=1.49, \mathrm{P}=0.005)$, liver $(\mathrm{IRR}=1.48, \mathrm{P}=0.002)$, leukemia $(\mathrm{IRR}=1.39, \mathrm{P}=$ $0.005)$, lung ( $I R R=1.39, P=0.039)$, breast $(I R R=1.38, P=0.011)$, and prostate cancers ( $I R R=2.11, P<0.001)$. Also, provinces with higher environmental friendliness and sustainability had significantly more stomach ( $\mathrm{IRR}=1.53, \mathrm{P}=0.004)$, colorectal $(1.79, \mathrm{P}<0.001)$, lung $(\mathrm{IRR}=1.43, \mathrm{P}=0.014)$, and prostate $(\mathrm{IRR}=1.50, \mathrm{P}=0.032)$ cancer incidence. Provinces with higher political governance had significantly more breast cancer $(I R R=1.34, P=0.002)$ and leukemia $(I R R=1.30, P=0.016)$ incidence rates.

Conclusions: Along with the development of urban liveability, the incidence of cancers is increasing in Iran. Cancer control strategies should be implemented especially in settings with higher urbanization.
\end{abstract}

Keywords: Liveability, Urbanization, Cancer, Incidence, Iran

\section{Background}

Urbanization is increasing in world populations and has dramatically changed human living environments (1). It is estimated that in $2050,68 \%$ of the world population will be living in urban dwellings (2). Therefore, the new concept of urban liveability has now attracted the attention of public health specialists and politicians. A livable community is a community that can provide the basic health and mental needs of residents such as security, social interaction and inclusion, environmental sustainability, affordable and diverse housing, leisure and cultural attractions, suitable employment, education, convenient public transport, walking and cycling paths, green spaces, local shops, accessible health, and community services (3). However, nowadays, many world cities have not only been unsuccessful in fulfilling these needs but are also struggling to manage crises such as noise pollution, traffic jams, unplanned population growth, slams, inappropriate housing, and deteriorating air quality (2).

Goal 11 from the sustainable development goals (SDG) of the united nations seeks to make cities more safe, resilient, and sustainable (4). Improving health is also a global priority for 2030, with SDG goal 3, focusing on promoting well-being for all ages (5).

The effects of urbanization on human health have been under scrutiny in some studies (1). Researchers think residing in cities, urban lifestyle, and socioeconomic status are among the main causes of the increased burden of noncommunicational diseases such as cancer and mental diseases. However, if urban planning is done according to liveability standards, some of this burden can be alleviated (57).

Global Cancer Incidence, Mortality, and Prevalence (GLOBOCAN) 2018 estimates that the shares of cancer cu- 
mulative incidence and age-standardized incidence rates (ASIR) per 100000 population in western Asia, Iran is a part of which, were 17.51 and 168.2, respectively. GLOBOCAN 2018 also estimates that the shares of cancer incidence and deaths were 48.4 and $57.3 \%$ in Asia, respectively (8), which is more than half of the world's deaths. World Health Organization (WHO) estimates that 9.6 million global deaths were caused by cancer in 2018, and approximately $70 \%$ of this mortality was from low- and middle-income countries (LMIC) (6).

Cancer control programs are among the main agenda for non-communicable disease (NCDs) control in Iran because cancer is the third most common cause of mortality following cardiovascular disease and road traffic accidents in this country. According to the results of the Iranian National Population-based Cancer Registry (INPCR) in 2014, the ASIRs of all cancers in Iran were 177.44 and 141.18 in 100000 males and females, respectively. This report also shows the geographical diversities in incidence rates of cancers in Iran (9). By matching the distribution of cancer incidence with environmental and urbanization risk factors, scientists can frame new theories for cancer etiology and provide recommendations for cancer prevention and public health resource allocation $(10,11)$. Urban infrastructure including sources of energy, noise pollution, transportation, shelter, air pollution, social isolation, sedentary behavior, unhealthy food, and tobacco use are important determinants of population health and health equity and can influence the risk of morbidity from chronic and mental diseases $(12,13)$. These risks are inequitably distributed in cities and, usually, the low socioeconomic groups have the highest exposure and worst prognosis. Researchers believe that cities produce systematic health inequities based on social status (14).

Nowadays, modern cities are increasingly focusing on determining and decreasing these inequities. At least 102 cities in 53 countries use the WHO's Urban Health Equity Assessment and Response Tool (Urban HEART) to analyze and plan for better health outcomes (5). There are national and subnational differences in the ways people understand cancer and their beliefs about this disease, what causes it, and how to prevent it. There are also differences in symptom presentation, access to early detection and diagnosis, participation in cancer screening programs, and access to preventive interventions around the world (15).

Iran is undergoing rapid urbanization. The proportion of Iran's urban population has grown to $75.4 \%$ in 2019 and is expected to increase to $86 \%$ by 2050 (16). Urbanization in Iran provides a unique opportunity to explore the mechanisms, by which urban liveability and urban environments influence cancer epidemiology. The associations between urbanization and cancer incidences have been reported in Iran and some other countries (17-21). However, the rela- tionship between cancer incidence and urban liveability remains largely unexplored with just a few exceptions (22, 23).

\section{Objectives}

In this study, we aimed at exploring the association of some urban liveability indicators and environmental risk factors with the incidence rates of 7 prevalent cancers in Iran, using province-level data.

\section{Methods}

\subsection{Study Population and Area}

Urban Liveability Index (ULI) and cancer incidence rates were inquired for all 31 provinces of Iran in 2016. The units of the analyses were provinces.

\subsection{Cancer Incidence Outcomes}

ASIR of 7 more prevalent cancers of Iran including lung, breast, prostate, stomach, colorectal, and liver cancer, and leukemia were inquired from the populationbased cancer registry of the Iranian Ministry of Health and Medical Education for 2016.

In this database, information of patients with cancer including their address of residence is included. In cases where the addresses do not match or there are several addresses for one patient, an investigation is done to find out the correct residing address of the individual. The officials of the cancer registry claim that the recorded addresses are more than $90 \%$ accurate.

The incidence rates for each cancer, in each province were calculated by the direct standardization method, using the age structure of the Segi-Doll's world population as the standard. A detailed description of this method can be found elsewhere (9).

\subsection{ULI Data}

The Global Liveable City Index (GLCI) was a framework employed by Tan et al. to construct the Asia Competitiveness Institute's (ACI's) liveability framework (2020). Since then, the GLCI framework has been used in several different studies (24). This framework ranks the liveability of cities by 5 themes (dimensions), each with several indicators, to operationalize measurement (24), which are: (1) economic vibrancy and competitiveness (28 indicators); (2) environmental friendliness \& sustainability (29 indicators); (3) domestic security \& stability (8 indicators); (4) socio-cultural conditions (43 indicators); (5) political governance (6 indicators).

In this study, these 114 practical indicators, under 5 domains, were used to estimate urban liveability. 
A detailed description of the indicators used in this study can be found elsewhere (25). Data about these indicators for the year 2016 were gathered from reliable sources, including statistical yearbooks, and reports from the Environmental Protection Agency, Ministry of Health and Medical Education, Ministry of Information and Communication, Department of Tourism and Cultural Heritage, and municipalities (25). The overall scores were divided based on the 33.3 and 66.7 percentiles into 3 categories (low, medium, and high).

\subsection{Statistical Analysis}

Each province was treated as a single observation. The main outcomes were ASIR of cancers. KolmogorovSmirnov test was used to test the normality of the data; and because the data were normal, the Pearson's correlation test was used to estimate the association between agestandardized cancer incidence rates and ULI and its domains. We also generated scatter plots to visualize the pattern of these correlations.

Given the count nature of the study outcomes that was the number of cancer cases in each province and the overdispersion of data, negative binomial (NB) regression was performed to estimate the incidence rate ratios (IRR) and their 95\% confidence intervals (CI). Explanatory variables were in three levels, below the 33rd percentile (low liveability), between the 33rd and 66th percentile (medium liveability), and above the 66th percentile (high liveability). We reported IRRs for the provinces in medium and high liveability versus those with low liveability. In these models, the total population of each province was considered the offset. Age was adjusted for all cancers, while the effect of sex was adjusted only for stomach, lung, colorectal, liver, and blood cancer. Statistical analyses were performed in Stata v14.0 (Stata crop, Texas, USA) and SPSS v 21.0. P-values less than 0.05 were considered significant.

\section{Results}

\subsection{Urban Liveability Index}

Urban liveability was calculated, using the GLCI method and the scores of 31 Iranian provinces ranged from -2.456 to 3.054 (Figure 1). Provinces were classified into 3 levels (low, moderate, and high) for each domain. Figure 1 shows the situation of provinces regarding total urban liveability and its domains. Provinces with higher scores, including Tehran, Mazandaran, and East Azerbaijan are the most livable provinces of the country.

\subsection{Cancer Incidence Rates}

In 2016, 57891 new cases of cancer were reported in all 31 provinces. ASIR for all cancers ranged from 77.09 per
100000 in Sistan and Baluchestan Province to 204.39 per 100000 in Yazd Province. The ASIRs of all cancers were 172.37 and 147.30 per 100000 in males and females, respectively, and after excluding non-melanoma skin cancer, they were 153.66 and 135.88 per 100000 in males and females, respectively. Cancers of breast $($ ASIR $=37.52)$, prostate $($ ASIR $=$ 20.13), stomach (ASIR=13.48), colorectal (ASIR=10.40), lung $($ ASIR $=8.19)$, liver $($ ASIR $=3.24)$, and leukemia $($ ASIR $=2.96)$ were the most common cancers in Iran in 2016. Figure 2 shows the age-specific incidence rates of the 7 most common cancers of Iran, in provinces, in 2016.

\subsection{Correlations Between Urban Liveability and Cancer Inci- dence Rates}

Cancer incidence had a strong and significant correlation with overall liveability, especially in breast $(\mathrm{r}=0.71, \mathrm{P}$ $<0.001)$, prostate $(\mathrm{r}=0.73, \mathrm{P}<0.001)$, and colorectal $(\mathrm{r}=$ $0.62, \mathrm{P}<0.001)$ cancers. Also, provinces with higher urban liveability had reported more leukemia, but it was not significant $(\mathrm{r}=0.33, \mathrm{P}=0.063)$. The correlation between liver, stomach, and lung cancer incidence rates with overall liveability was not statistically significant either (Table 1, Figure 3). Correlations between cancer incidence rates and the domains of urban liveability are presented in Table 1.

Table 2 depicts the distribution and demographic characteristics of patients with cancer in low, medium, and high liveability provinces of Iran.

Regression analyses also showed that provinces with higher urban liveability had a higher likelihood of cancer incidence and this association was statistically significant for all cancers, except for liver and stomach cancer. Provinces with a higher overall urban liveability had a higher incidence of colorectal cancer $(I R R=1.57, P=0.002)$, leukemia $(\mathrm{IRR}=1.48, \mathrm{P}=0.002)$, breast cancer $(\mathrm{IRR}=1.26, \mathrm{P}$ $=0.045)$, prostate cancer $(\mathrm{IRR}=1.66, \mathrm{P}=0.005)$, and lung cancer $(\mathrm{IRR}=1.45, \mathrm{P}=0.009)$ (Table 3$)$.

Provinces with higher scores in the domains had also reported higher incidence rates for some cancers. Provinces with higher economic vibrancy and competitiveness had significantly more colorectal, liver, leukemia, lung, breast, and prostate cancer incidence rates.

Also, provinces with higher environmental friendliness and sustainability showed significantly more stomach, colorectal, lung, and prostate cancer incidence.

Meanwhile, provinces with higher domestic security and stability had significantly more leukemia and lung cancer, and provinces with high political governance had significantly more breast cancer and leukemia compared with low-level provinces (Table 3 ).

\section{Discussion}

This study shows that in Iran provinces with better urban liveability had higher rates of cancer incidence, par- 


\begin{tabular}{|c|c|c|c|c|c|c|}
\hline Province & $\begin{array}{c}\text { Overall } \\
\text { Liveability }\end{array}$ & $\begin{array}{c}\text { Economic and } \\
\text { Competitiveness }\end{array}$ & $\begin{array}{c}\text { Environmental \& } \\
\text { Sustainability }\end{array}$ & $\begin{array}{l}\text { Security \& } \\
\text { Stability }\end{array}$ & $\begin{array}{c}\text { Socio } \\
\text { cultural }\end{array}$ & $\begin{array}{c}\text { Political } \\
\text { Governance }\end{array}$ \\
\hline Tehran & 3.054 & 3.289 & 1.019 & -0.743 & 2.93 & 3.768 \\
\hline Mazandaran & 2.385 & 2.338 & 0.823 & 0.471 & 3.468 & 0.915 \\
\hline East Azerbaijan & 1.243 & 0.92 & 1.486 & 1.965 & -0.517 & 0.324 \\
\hline Isfahan & 0.794 & 0.521 & 0.511 & 0.249 & 1.232 & 0.157 \\
\hline Yazd & 0.558 & -0.159 & 0.165 & 0.399 & 1.892 & -0.42 \\
\hline Fars & 0.53 & 0.607 & 0.577 & 0.766 & -1.021 & 0.852 \\
\hline Khuzestan & 0.529 & 0.802 & 0.347 & 0.319 & -0.193 & 0.503 \\
\hline Qazvin & 0.445 & -0.009 & 0.429 & 1.023 & 0.057 & -0.005 \\
\hline Semnan & 0.433 & -0.012 & 0.512 & -2.681 & 2.295 & 1.341 \\
\hline Guilan & 0.256 & 0.641 & 0.351 & 0.283 & -0.424 & 0.011 \\
\hline Alborz & 0.187 & 1.095 & 0.201 & -2.803 & 2.051 & 0.086 \\
\hline Golestan & 0.043 & 0.175 & 0.072 & -0.109 & -0.523 & 0.532 \\
\hline Ardabil & 0.005 & -0.021 & 1.159 & 0.757 & -0.58 & -1.298 \\
\hline Razavi Khorasan & -0.095 & 0.257 & 1.051 & -0.404 & -0.551 & -0.671 \\
\hline Ilam & -0.115 & -0.439 & 0.71 & 0.457 & -1.665 & 0.547 \\
\hline South Khorasan & -0.133 & -1.425 & 1.078 & -0.101 & -0.301 & 0.299 \\
\hline Hormozgan & -0.185 & -0.746 & -1.595 & 0.056 & 1.438 & 0.224 \\
\hline Qom & -0.258 & 0.273 & -0.139 & -1.197 & 0.115 & 0.079 \\
\hline Bushehr & -0.291 & -0.329 & -2.337 & 0.377 & 0.939 & 0.373 \\
\hline Zanjan & -0.293 & -1.131 & -0.162 & 0.865 & 0.339 & -0.898 \\
\hline West Azerbaijan & -0.387 & -1.119 & 0.128 & 0.378 & 0.171 & -0.861 \\
\hline Markazi & -0.426 & -0.454 & -0.348 & -0.157 & -0.262 & -0.211 \\
\hline Kurdistan & -0.475 & -0.641 & 0.327 & 1.255 & -0.771 & -1.769 \\
\hline Hamadan & -0.51 & -0.0004 & -0.218 & 0.481 & -1.168 & -0.811 \\
\hline $\begin{array}{l}\text { Chaharmahal and } \\
\text { Bakhtiari }\end{array}$ & -0.523 & -0.615 & -0.462 & 0.571 & -0.572 & -0.679 \\
\hline $\begin{array}{l}\text { Kohgiluyeh and } \\
\text { BoyerAhmad }\end{array}$ & -0.591 & -0.931 & 0.112 & -0.151 & -0.446 & -0.569 \\
\hline Kermanshah & -0.713 & -1.195 & -0.074 & -1.416 & -0.273 & 0.563 \\
\hline Kerman & -0.772 & -0.164 & -1.988 & 0.177 & -0.345 & -0.274 \\
\hline North Khorasan & -0.977 & -0.866 & -0.059 & 0.011 & -1.512 & -0.856 \\
\hline Lorestan & -1.262 & -0.501 & -1.027 & -0.632 & -0.827 & -1.252 \\
\hline $\begin{array}{l}\text { Sistan and } \\
\text { Baluchestan }\end{array}$ & -2.456 & -0.161 & -2.647 & -0.471 & -4.976 & 0.001 \\
\hline
\end{tabular}

Figure 1. Urban Liveability Index scores in different domains for each Iranian province. The green, yellow, and red colors indicate low, medium, and high liveability scores, respectively.

\begin{tabular}{|c|c|c|c|c|c|c|c|c|c|c|c|c|c|c|}
\hline \multirow{2}{*}{ Variables } & \multicolumn{2}{|c|}{ Lung } & \multicolumn{2}{|c|}{ Breast } & \multicolumn{2}{|c|}{ Prostate } & \multicolumn{2}{|c|}{ Stomach } & \multicolumn{2}{|c|}{ Colorectal } & \multicolumn{2}{|c|}{ Liver } & \multicolumn{2}{|c|}{ Leukemia } \\
\hline & $\mathbf{r}$ & P.v & $\mathbf{r}$ & P.v & $\mathbf{r}$ & P.v & $\mathbf{r}$ & P.v & $\mathbf{r}$ & P.v & $\mathbf{r}$ & P.v & $\mathbf{r}$ & P.v \\
\hline Overall liveability & 0.11 & 0.591 & $0.71^{\mathrm{a}}$ & $<0.001^{\mathrm{a}}$ & $0.73^{\mathrm{a}}$ & $<0.001^{\mathrm{a}}$ & 0.12 & 0.510 & $0.62^{\mathrm{a}}$ & $<0.001^{\mathrm{a}}$ & -0.14 & 0.440 & 0.33 & 0.063 \\
\hline Economic vibrancy and competitiveness & 0.02 & 0.936 & $0.71^{\mathrm{a}}$ & $<0.001^{\mathrm{a}}$ & $0.73^{\mathrm{a}}$ & $<0.001^{\mathrm{a}}$ & 0.05 & 0.790 & $0.51^{\mathrm{a}}$ & $0.004^{\mathrm{a}}$ & -0.21 & 0.269 & 0.17 & 0.362 \\
\hline Environmental friendliness \& sustainability & 0.07 & 0.724 & 0.32 & 0.075 & $0.40^{\mathrm{a}}$ & $0.028^{\mathrm{a}}$ & $0.55^{\mathrm{a}}$ & $<0.001^{\mathrm{a}}$ & $0.68^{\mathrm{a}}$ & $<0.001^{\mathrm{a}}$ & 0.01 & 0.956 & 0.25 & 0.179 \\
\hline Domestic security \& stability & 0.22 & 0.240 & -0.23 & 0.219 & -0.02 & 0.899 & 0.21 & 0.253 & -0.13 & 0.488 & 0.19 & 0.293 & 0.35 & 0.056 \\
\hline Socio-cultural conditions & 0.08 & 0.678 & $0.58^{\mathrm{a}}$ & $<0.001^{\mathrm{a}}$ & $0.53^{\mathrm{a}}$ & $0.002^{\mathrm{a}}$ & -0.08 & 0.666 & $0.43^{\mathrm{a}}$ & $0.015^{\mathrm{a}}$ & -0.23 & 0.214 & 0.17 & 0.348 \\
\hline Political governance & -0.08 & 0.657 & $0.66^{\mathrm{a}}$ & $<0.001^{\mathrm{a}}$ & $0.52^{\mathrm{a}}$ & $0.003^{\mathrm{a}}$ & -0.27 & 0.141 & 0.35 & 0.053 & -0.12 & 0.508 & 0.09 & 0.601 \\
\hline
\end{tabular}

${ }^{2}$ Abbreviations: r, the correlation coefficient; p-v: P-value

a Estimates with significant P-values at below $5 \%$ level.

ticularly for prostate, colorectal, and breast cancer. Also, provincial-level, economic conditions, environmental sustainability, domestic security, and political governance performance were directly associated with cancer incidence. According to GLOBOCAN and local reports (26), Iran is a medium-risk country for cancer incidence. There is a notable diversity in the incidence of different types of cancer in different provinces of Iran and cancer has had an in- creasing trend in Iran in recent years (9).

In Iran, provinces with higher rates of urbanization and liveability are more likely to have a higher prevalence of NCD risk factors, which include low physical activity, obesity, and unhealthy diets (9). Rapid urbanization coupled with lifestyle changes and socio-economic development has led to changes in the pattern of health outcomes in cities (5). Historically, in LMICs, overweight and obesity 


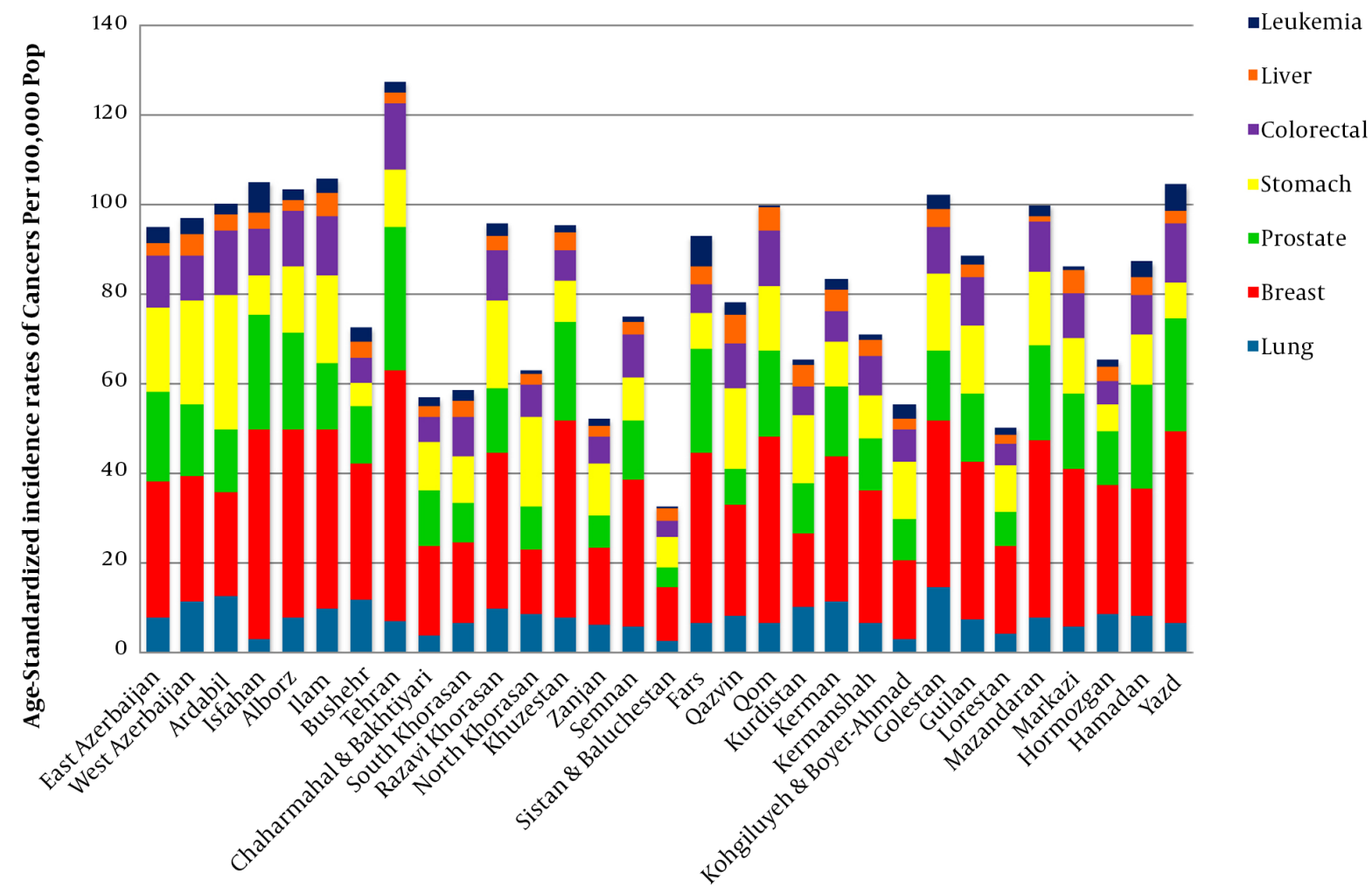

Figure 2. Age-specific incidence rates (per 100 000) of the most common cancers in Iran in 2016

were associated with high income. But, in richer countries, overweight and obesity are more common among the low socioeconomic groups (27).

A study conducted on 122 countries in 2018 showed that the incidence rate of all cancers directly increases as per capita income increases, and this relationship remained even after controlling for population aging. Economic development may cause higher life expectancy by improved and early cancer detection and case reporting but maybe also associated with environmental pollution and unhealthy lifestyles (22).

An ecological study conducted on 49 European countries reported that prostate cancer incidence varied more than 15-fold across the world, and was highest in highincome countries. Also, healthcare expenditure $(\mathrm{RR}=$ 1.46) and population growth $(R R=1.15)$, as well as computer $(R R=1.43)$, and mobile phone density $(R R=1.07)$ were associated with a higher incidence of prostate cancer, while the gross domestic product $(\mathrm{GDP})(\mathrm{RR}=0.94)$ was inversely associated with prostate cancer (28). Another global study based on GLOBOCAN 2012 data reported that age-standardized incidence and mortality rates of lung cancer were both directly correlated with Human Develop- ment Index (HDI) $(r=0.70, r=0.67)$, and country-specific GDP per capita $(r=0.24, r=0.55)(29)$.

Researchers have reported direct associations between PM2.5 levels and age-adjusted respiratory cancer incidence rates (30). The increasing lung cancer incidence rates in Iran are occurring along with increasing rates of environmental pollution, urbanization, and smoking (31).

According to the WHO report, air pollution, tobacco smoking, radiation, chemicals, and occupational risk factors are responsible for at least $20 \%$ of disability-adjusted life years coming from patients with cancer (32). These risk factors are more prevalent in urban than rural settings.

In a study conducted from 2006 to 2010 on 2687 counties in the United States, Environmental Quality Index (EQI) was used as an indicator of cumulative environmental exposures at the county level. Poor environmental quality was directly associated with all-site cancer incidence rates in the total population and male and female subgroups (33). Other studies have shown a strong positive relationship between the incidence of breast and prostate cancer and poor environmental (air, water, soil) quality (33) as well.

The incidence of cancer is also affected by genetic fac- 

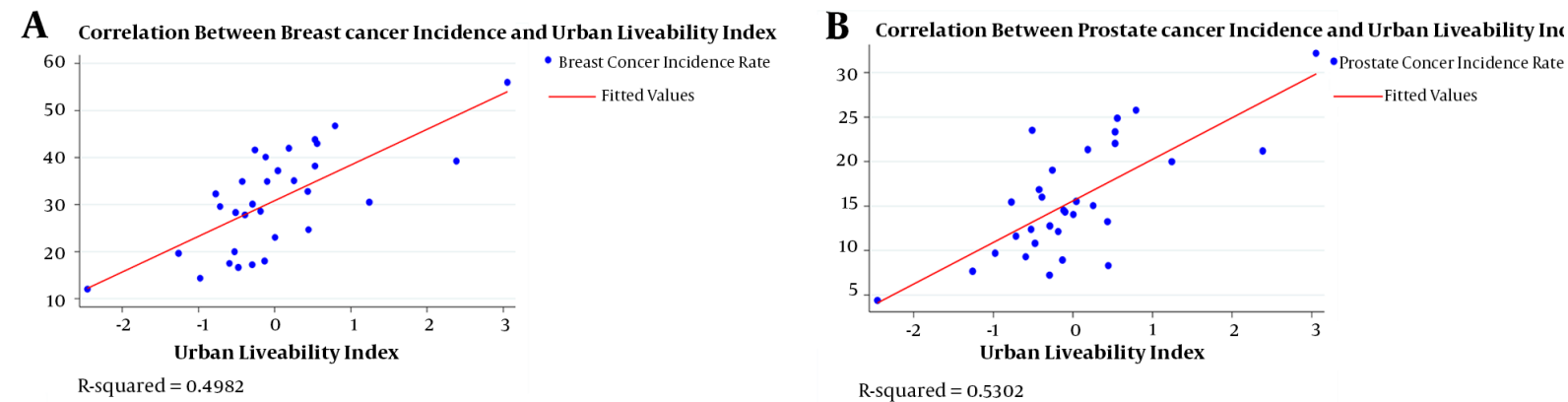

C Correlation Between Colorectal cancer Incidence and Urban Liveability Index
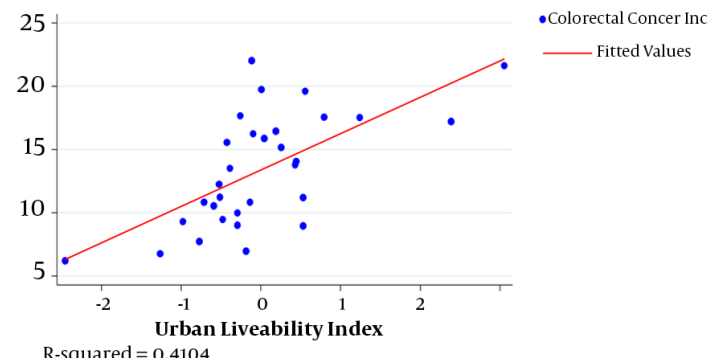

$\mathbf{E}$ R-squared $=0.4104$

D Correlation Between Stomach cancer Incidence and Urban Liveability Inc
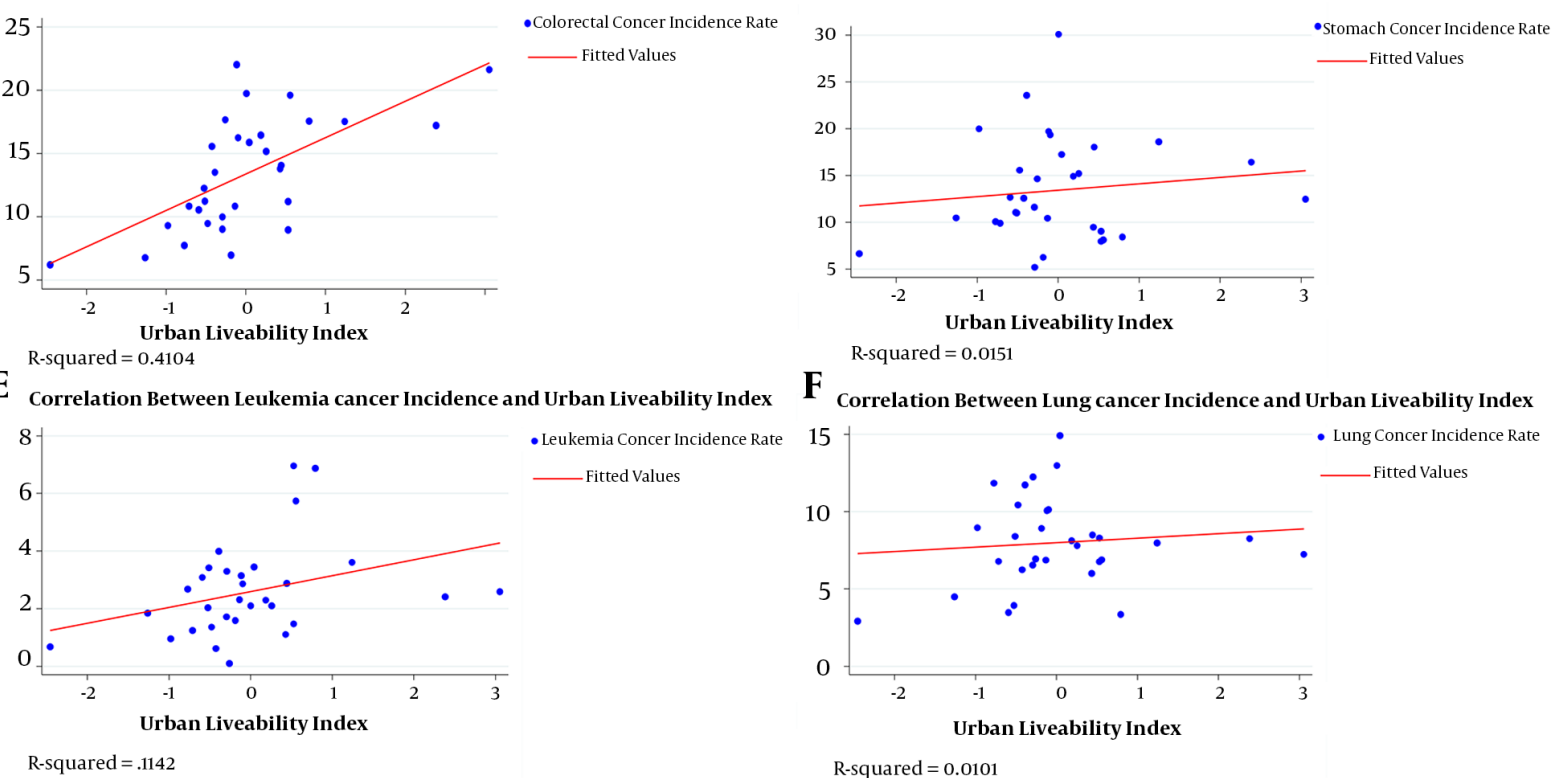
R-squared $=0.0151$

$\mathbf{F}$

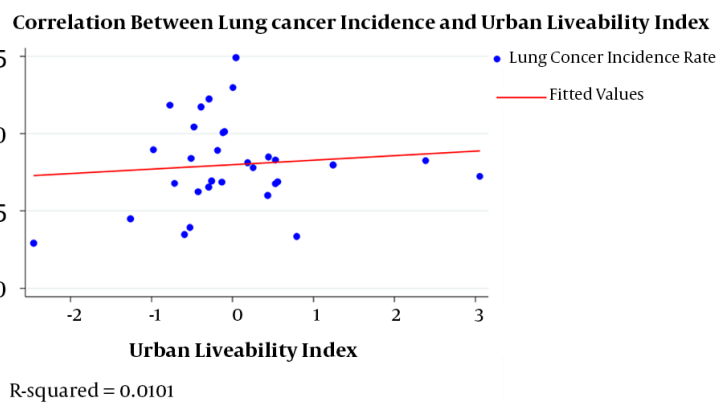

Figure 3. The provincial-level correlation of the overall urban liveability index with breast (A), prostate (B), colorectal(C), stomach (D), leukemia (E), and lung cancer incidence (F).

tors. Recent research suggests that specific genetic subtypes can interact with environmental exposures and this can exacerbate the effects of harmful exposures and increase the risk of cancer $(33,34)$. Our results showed positive associations between prostate cancer incidences and domestic security and stability. Although we did not find any article about the relationship between cancer and domestic security and stability, it is likely that in regions with more security and stability, prostate cancer cases, which are commonly old men, are diagnosed more frequently; whereas in societies with low security and stability, because of a shorter lifetime, engagement in war, violence or poverty, men do not get screened for prostate cancer. A study conducted over 38 years in Finland showed that colon cancer incidence was on average higher among those with high education and high SES compared to those with lower education and low SES (35). In Europe, most studies have reported that colon cancer was more common in high SES groups $(35,36)$. A systematic review from 18 cohort studies also showed that higher education may be associated with an increased risk of breast cancer, and alcohol use and hormone therapy may play a mediating role (37).

Urbanization has affected public health with complicated mechanisms such as a change in the regional environment, land use, transportation, air quality, food safety, and lifestyle (1).

Urban residents have a faster pace of life and suffer from stress, heavier workload, less physical activity, and unhealthy eating and living habits and this lifestyle can make them more prone to cancer (38). A study in China showed that rapid urbanization changed people's situation by changing land use, causing air, water, food, and soil pollution, imposing less physical activity, and expos- 


\begin{tabular}{|c|c|c|c|c|c|c|c|}
\hline \multirow{2}{*}{ Demographic Characteristic/The Urban Liveability } & \multicolumn{7}{|c|}{ Cancers } \\
\hline & Stomach & Colorectal & Liver & Leukemia & Lung & Breast & Prostate \\
\hline \multicolumn{8}{|l|}{ Patient, No. (\%) } \\
\hline Low & $1741(17)$ & $1466(13.6)$ & $578(23.3)$ & $827(16.1)$ & $1094(17.8)$ & $1990(13.7)$ & 966 (14.9) \\
\hline Medium & $3409(33.4)$ & $2883(26.8)$ & $694(28)$ & $1411(27.4)$ & $1941(31.6)$ & 3549 (24.4) & $1405(21.6)$ \\
\hline High & 5055 (49.5) & $6406(59.5)$ & $1211(48.7)$ & $2914(56.6)$ & $3113(50.6)$ & 9009 (61.9) & 4122 (63.5) \\
\hline \multicolumn{8}{|l|}{ Mean age (SD) } \\
\hline Low & $66.93(14.9)$ & $60.55(15.6)$ & $67.66(17.1)$ & $43.54(31.2)$ & $66.26(14.4)$ & 51.85 (13.7) & $72.77(11.1)$ \\
\hline Medium & $67.38(18.3)$ & $62.17(23.2)$ & $64.62(18.2)$ & $47.55(34.1)$ & $66.68(20.8)$ & $51.91(14.2)$ & $73.41(10.6)$ \\
\hline High & $66.97(14.3)$ & $62.05(14.6)$ & $65.25(18.4)$ & $48.27(34.6)$ & $65.37(14.1)$ & $52.15(13.8)$ & $71.72(13.6)$ \\
\hline \multicolumn{8}{|l|}{ Age range $(y)$} \\
\hline Low & $3-113$ & 9-99 & $2-109$ & $1-107$ & $4-100$ & $11-100$ & $19-116$ \\
\hline Medium & $4-101$ & 3-101 & $1-105$ & $1-100$ & $4-104$ & $11-115$ & $25-106$ \\
\hline High & $6-100$ & $3-97$ & $1-99$ & $1-100$ & $3-96$ & $11-98$ & $23-100$ \\
\hline \multicolumn{8}{|l|}{ Sex, No(\%) } \\
\hline \multicolumn{8}{|l|}{ Male } \\
\hline Low & $1173(17.1)$ & $773(12.8)$ & $374(25.1)$ & $494(15.8)$ & $770(18)$ & - & $966(14.9)$ \\
\hline Medium & $2260(32.9)$ & $1633(27)$ & $425(28.5)$ & $857(27.5)$ & $1303(30.5)$ & - & $1405(21.6)$ \\
\hline High & $3432(49.9)$ & $3646(60.2)$ & $692(46.4)$ & $1769(56.7)$ & $2199(51.5)$ & - & $4122(63.5)$ \\
\hline \multicolumn{8}{|l|}{ Female } \\
\hline Low & $568(17)$ & $693(14.7)$ & $204(20.6)$ & $333(16.4)$ & $324(17.4)$ & 1990 (13.7) & - \\
\hline Medium & $1150(34.4)$ & $1246(26.5)$ & $269(27.1)$ & $554(27.3)$ & $627(33.6)$ & 3549 (24.4) & - \\
\hline High & $1622(48.6)$ & $2760(58.7)$ & $519(52.3)$ & $1145(56.3)$ & $915(49)$ & $9009(61.9)$ & - \\
\hline
\end{tabular}

ing people to electromagnetic radiation, which can cause cancer (1).

The province's adherence to the rule of law was well correlated with its cancer incidence, especially in breast, prostate, and leukemia. Corruption plays a detrimental role in healthcare systems and can damage the structure of healthcare systems in providing cancer care. In corrupted societies, where resources are not evenly distributed, poor families are not covered by healthcare and it prevents them from seeking medical advice and getting diagnosed because even if properly diagnosed, they are not able to pay for the high cost of cancer treatment. The devastating effects of corruption on cancer care have been shown in different sections such as healthcare providers, drug and medical equipment distribution, and treatment (39). Klomp and de Haan analyzed 101 countries about the relationship between governance, the health of individuals, and the healthcare sector. Their results showed that after controlling economic and demographic variables, governance was not directly related to the health of individuals; however, governance indirectly influenced health via its positive impact on income and the quality of healthcare
(40).

Samuel conducted a study on 96 countries and showed that the higher the countries' level of adherence to the rule of law, the better the health of the population. Health advocates should consider that improvements in implementing the law can improve population health (41).

On the other hand, the systems of reporting epidemiological figures in these higher HDI provinces are generally more robust, and the low incidence of cancer in provinces with low governance might be because of not reporting the cases and not less incidence (29, 42). Hence, data should be interpreted with caution when these incidences are compared across provinces.

\subsection{Limitations}

This study had some limitations. One of the limitations is the ecological nature of the study, which precludes causality. Our results, however, do reveal an association between provincial macro indicators with levels of cancer incidence. Also, we have to keep in mind that the concept of liveability is population-based and it does not make sense for an individual. 
Khorrami Z et al.

\begin{tabular}{|c|c|c|c|c|c|c|c|c|}
\hline \multirow{2}{*}{ The Urban Liveability Score } & \multicolumn{2}{|c|}{ Stomach Cancer } & \multicolumn{2}{|c|}{ Colorectal Cancer } & \multicolumn{2}{|c|}{ Liver Cancer } & \multicolumn{2}{|c|}{ Leukemia Cancers } \\
\hline & $\operatorname{IRR}(95 \% \mathrm{CI})$ & P.Value & $\operatorname{IRR}(95 \% \mathrm{CI})$ & P-Value & $\operatorname{IRR}(95 \% \mathrm{CI})$ & P-Value & $\operatorname{IRR}(95 \% \mathrm{CI})$ & P-Value \\
\hline \multicolumn{9}{|l|}{ Overall liveability } \\
\hline Low & Ref & & Ref & & Ref & & Ref & \\
\hline Medium & $1.20(0.87-1.66)$ & 0.262 & $1.31(0.98-1.76)$ & 0.066 & $1.01(0.75-1.37)$ & 0.912 & $1.28(1.02-1.61)^{a}$ & $0.032^{\mathrm{a}}$ \\
\hline High & $1.14(0.83-1.57)$ & 0.387 & $1.57(1.17-2.11)^{\mathrm{a}}$ & $0.002^{\mathrm{a}}$ & $0.94(0.69-1.29)$ & 0.737 & $1.48(1.15-1.90)^{\mathrm{a}}$ & $0.002^{\mathrm{a}}$ \\
\hline \multicolumn{9}{|c|}{ Economic vibrancy and competitiveness } \\
\hline Low & Ref & & $\operatorname{Ref}^{\mathrm{a}}$ & & Ref & & Ref & \\
\hline Medium & $1.12(0.82-1.54)$ & 0.455 & $1.34(1.02-1.77)^{\mathrm{a}}$ & $0.033^{\mathrm{a}}$ & $1.48(1.15-1.90)^{\mathrm{a}}$ & $0.002^{\mathrm{a}}$ & $1.20(0.97-1.50)$ & 0.089 \\
\hline High & $1.17(0.85-1.61)$ & 0.310 & $1.49(1.12-1.98)^{a}$ & $0.005^{\mathrm{a}}$ & $1.22(0.94-1.58)$ & 0.127 & $1.39(1.10-1.75)^{a}$ & $0.005^{\mathrm{a}}$ \\
\hline \multicolumn{9}{|c|}{ Environmental friendliness \& sustainability } \\
\hline Low & Ref & & Ref & & Ref & & Ref & \\
\hline Medium & $1.45(1.09-1.93)^{\mathrm{a}}$ & $0.009^{\mathrm{a}}$ & $1.47(1.17-1.85)^{\mathrm{a}}$ & $0.001^{\mathrm{a}}$ & $1.03(0.79-1.35)$ & 0.796 & $0.97(0.75-1.26)$ & 0.872 \\
\hline High & $1.53(1.14-2.05)^{\mathrm{a}}$ & $0.004^{\mathrm{a}}$ & $1.79(1.41-2.28)^{a}$ & $<0.001^{\mathrm{a}}$ & $0.95(0.71-1.25)$ & 0.718 & $1.08(0.81-1.43)$ & 0.571 \\
\hline \multicolumn{9}{|l|}{ Domestic security \& stability } \\
\hline Low & Ref & & Ref & & Ref & & Ref & \\
\hline Medium & $1.09(0.81-1.47)$ & 0.542 & $0.95(0.71-1.27)$ & 0.748 & $1.11(0.85-1.45)$ & 0.412 & $1.34(1.07-1.69)^{a}$ & $0.010^{\mathrm{a}}$ \\
\hline High & $1.36(0.99-1.86)$ & 0.053 & $1.11(0.82-1.49)$ & 0.492 & $1.14(0.87-1.50)$ & 0.335 & $1.13(0.89-1.42)$ & 0.296 \\
\hline \multicolumn{9}{|l|}{ Socio-cultural conditions } \\
\hline Low & Ref & & Ref & & Ref & & Ref & \\
\hline Medium & $0.92(0.67-1.26)$ & 0.624 & $1.07(0.80-1.45)$ & 0.615 & $1.18(0.92-1.51)$ & 0.173 & $1.15(0.91-1.46)$ & 0.217 \\
\hline High & $0.78(0.53-1.07)$ & 0.127 & $1.12(0.82-1.54)$ & 0.454 & $0.82(0.63-1.07)$ & 0.158 & $1.12(0.88-1.44)$ & 0.338 \\
\hline \multicolumn{9}{|l|}{ Political governance } \\
\hline Low & Ref & & Ref & & Ref & & Ref & \\
\hline Medium & $0.81(0.59-1.12)$ & 0.215 & $1.08(0.80-1.45)$ & 0.584 & $1.26(0.96-1.64)$ & 0.088 & $1.38(1.11-1.71)^{\mathrm{a}}$ & $0.003^{\mathrm{a}}$ \\
\hline High & $0.88(0.64-1.20)$ & 0.432 & $1.24(0.92-1.67)$ & 0.142 & $1.07(0.79-1.46)$ & 0.625 & $1.30(1.05-1.62)^{\mathrm{a}}$ & $0.016^{\mathrm{a}}$ \\
\hline \multirow{2}{*}{ The Urban Liveability Score } & \multicolumn{2}{|c|}{ Lung Cancer } & \multicolumn{3}{|c|}{ Breast Cancer } & \multicolumn{3}{|c|}{ Prostate Cancer } \\
\hline & $\operatorname{IRR}(95 \% \mathrm{CI})$ & P-Value & $\operatorname{IRR}(95 \% \mathrm{CI})$ & & P-Value & $\operatorname{IRR}(95 \% \mathrm{CI})$ & P-Valu & \\
\hline \multicolumn{9}{|l|}{ Overall liveability } \\
\hline Low & Ref & & Ref & & & Ref & & \\
\hline Medium & $1.45(1.09-1.91)^{\mathrm{a}}$ & $0.009^{\mathrm{a}}$ & $1.12(0.92-1.36)$ & & 0.255 & $1.02(0.72-1.45)$ & 0.890 & \\
\hline High & $1.21(0.91-1.61)$ & 0.178 & $1.26(1.05-1.58)^{\mathrm{a}}$ & & $0.045^{\mathrm{a}}$ & $1.66(1.16-2.36)^{\mathrm{a}}$ & 0.005 & \\
\hline \multicolumn{9}{|c|}{ Economic vibrancy and competitiveness } \\
\hline Low & Ref & & Ref & & & Ref & & \\
\hline Medium & $1.36(1.01-1.82)^{\mathrm{a}}$ & $0.039^{\mathrm{a}}$ & $1.20(0.98-1.47)$ & & 0.076 & $1.43(1.03-1.98)^{\mathrm{a}}$ & $0.031^{2}$ & \\
\hline High & $1.15(0.86-1.54)$ & 0.336 & $1.38(1.07-1.77)^{\mathrm{a}}$ & & $0.011^{\mathrm{a}}$ & $2.11(1.48-3.02)^{\mathrm{a}}$ & $<0.000$ & \\
\hline \multicolumn{9}{|c|}{ Environmental friendliness \& sustainability } \\
\hline Low & Ref & & Ref & & & Ref & & \\
\hline Medium & $1.22(0.92-1.63)$ & 0.156 & $1.19(0.98-1.43)$ & & 0.068 & $1.16(0.80-1.67)$ & 0.424 & \\
\hline High & $1.43(1.07-1.91)^{\mathrm{a}}$ & $0.014^{\mathrm{a}}$ & $1.21(0.99-1.48)$ & & 0.060 & $1.50(1.03-2.18)^{\mathrm{a}}$ & $0.032^{\mathrm{a}}$ & \\
\hline \multicolumn{9}{|l|}{ Domestic security \& stability } \\
\hline Low & Ref & & Ref & & & Ref & & \\
\hline Medium & $1.38(1.03-1.86)^{\mathrm{a}}$ & $0.029^{\mathrm{a}}$ & $1.19(0.99-1.45)$ & & 0.063 & $1.14(0.77-1.68)$ & 0.491 & \\
\hline High & $1.37(1.01-1.86)^{\mathrm{a}}$ & $0.041^{\mathrm{a}}$ & $1.03(0.85-1.25)$ & & 0.716 & $1.19(0.80-1.78)^{\mathrm{a}}$ & $0.377^{\mathrm{a}}$ & \\
\hline Socio-cultural conditions & & & & & & & & \\
\hline Low & Ref & & Ref & & & Ref & & \\
\hline Medium & $1.03(0.76-1.40)$ & 0.817 & $1.18(0.97-1.44)$ & & 0.084 & $1.18(0.81-1.72)$ & 0.385 & \\
\hline High & $1.08(0.79-1.48)$ & 0.592 & $1.08(0.87-1.35)$ & & 0.437 & $1.44(0.97-2.13)$ & 0.065 & \\
\hline Political governance & & & & & & & & \\
\hline Low & Ref & & Ref & & & Ref & & \\
\hline Medium & $0.88(0.66-1.19)$ & 0.437 & $1.08(0.89-1.31)$ & & 0.389 & $1.24(0.84-1.81)$ & 0.263 & \\
\hline High & $1.09(0.80-1.48)$ & 0.583 & $1.34(1.11-1.61)^{a}$ & & $0.002^{\mathrm{a}}$ & $1.31(0.87-1.98)$ & 0.188 & \\
\hline
\end{tabular}

${ }_{\mathrm{a}}^{\mathrm{z}}$ Abbreviations: IRR, incidence rate ratio; Cl, confidence intervals.

a Estimates with significant P-values at below $5 \%$ level. 
Another limitation of the study was that the Iranian Cancer Registry does not collect comprehensive information on personal characteristics, such as comorbidities, or financial and marital status, and we could not control these variables.

However, this study used and analyzed the most reliable data of cancer and showed the geographical variations of cancer incidence in Iran.

Cancer control strategies should be implemented according to local situations in Iranian provinces and require multisector collaboration across many sectors such as healthcare, medical services, urban planning, education, finance, commerce, regulation, and others. A greater emphasis on primary prevention and early detection is needed to alleviate the effect of aging and population growth on the burden of cancers in Iran.

\subsection{Conclusions}

Along with the development of urban liveability, the incidence of cancers is increasing in Iran. Cancer control strategies should be implemented especially in settings with higher urbanization. This pattern also shows that urbanization may be adversely affecting human health in ways not fully understood. Further research is needed to improve the health necessities of urban dwellers.

\section{Acknowledgments}

We thank the Environmental Protection Agency, Ministry of Health and Medical Education, Ministry of Information and Communication, Department of Tourism and Cultural Heritage, and municipalities in Iran for providing the data needed for this study.

\section{Footnotes}

Authors' Contribution: ZK, conceptualization, methodology, formal analysis, writing the original draft, and visualization; NK, conceptualization, methodology, writing, editing, and supervision; MM and FD, methodology, data acquisition, writing, editing, administration support; MM, methodology, data acquisition, writing, editing, reviewing statistical analyzes. All authors reviewed and approved the final manuscript.

Conflict of Interests: There is no conflict of interest. Funding/Support: There is no funding/support.

\section{References}

1. Liu JL, Li XH, Lin T, Dai L, Zhang GQ, Zhang CS, et al. Spatial analysis of gastric cancer morbidity in regions of rapid urbanization: A case study in Xiamen, China. Stoch Environ Res Risk Assess. 2015;30(2):71323. doi: 10.1007/s00477-015-1141-2.
2. Giles-Corti B, Lowe M, Arundel J. Achieving the SDGs: Evaluating indicators to be used to benchmark and monitor progress towards creating healthy and sustainable cities. Health Policy. 2020;124(6):581-90. doi: 10.1016/j.healthpol.2019.03.001. [PubMed: 30935701].

3. Lowe M, Arundel J, Hooper P, Rozek J, Higgs C, Roberts R, et al. Liveability aspirations and realities: Implementation of urban policies designed to create healthy cities in Australia. Soc Sci Med. 2020;245:112713. doi: 10.1016/j.socscimed.2019.112713. [PubMed: 31855727].

4. Weimann A, Oni T. A systematised review of the health impact of urban informal settlements and implications for upgrading interventions in South Africa, a rapidly urbanising middle-income country. Int J Environ Res Public Health. 2019;16(19). doi: 10.3390/ijerph16193608. [PubMed: 31561522]. [PubMed Central: PMC6801583].

5. World Health Organization. Global report on urban health: equitable healthier cities for sustainable development. Geneva, Switzerland: World Health Organization; 2016.

6. World Health Organization. Cancer. Geneva, Switzerland: World Health Organization; 2021. Available from: https://www.who.int/ news-room/fact-sheets/detail/cancer.

7. Yang H, Pu H, Wang S, Ni R, Li B. Inequality of female health and its relation with urbanization level in China: Geographic variation perspective. Environ Sci Pollut Res Int. 2019;26(16):16662-73. doi: 10.1007/s11356019-04555-x. [PubMed: 30989606].

8. Bray F, Ferlay J, Soerjomataram I, Siegel RL, Torre LA, Jemal A. Global cancer statistics 2018: GLOBOCAN estimates of incidence and mortality worldwide for 36 cancers in 185 countries. CA Cancer J Clin. 2018;68(6):394-424. doi: 10.3322/caac.21492. [PubMed: 30207593].

9. Roshandel G, Ghanbari-Motlagh A, Partovipour E, Salavati F, Hasanpour-Heidari S, Mohammadi G, et al. Cancer incidence in Iran in 2014: Results of the Iranian National Population-based Cancer Registry. Cancer Epidemiol. 2019;61:50-8. doi: 10.1016/j.canep.2019.05.009. [PubMed: 31132560].

10. Fei X, Chen W, Zhang S, Liu Q, Zhang Z, Pei Q. The spatio-temporal distribution and risk factors of thyroid cancer during rapid urbanization-A case study in China. Sci Total Environ. 2018;630:143645. doi: 10.1016/j.scitotenv.2018.02.339. [PubMed: 29554762].

11. Fei X, Lou Z, Christakos G, Liu Q, Ren Y, Wu J. Contribution of industrial density and socioeconomic status to the spatial distribution of thyroid cancer risk in Hangzhou, China. Sci Total Environ. 2018;613614:679-86. doi: 10.1016/j.scitotenv.2017.08.270. [PubMed: 28938210].

12. Giles-Corti B, Vernez-Moudon A, Reis R, Turrell G, Dannenberg AL, Badland $\mathrm{H}$, et al. City planning and population health: A global challenge. Lancet. 2016;388(10062):2912-24. doi: 10.1016/S0140-6736(16)30066-6. [PubMed: 27671668].

13. Juma K, A. Juma P, Shumba C, Otieno P, Asiki G. Non-communicable diseases and urbanization in African cities: A narrative review. In: Anugwom EE, Awofeso N, editors. Public health in developing countries. London, UK: InTechOpen; 2020. doi: 10.5772/intechopen.89507.

14. Buttazzoni A, Veenhof M, Minaker L. Smart city and high-tech urban interventions targeting human health: An equity-focused systematic review. Int J Environ Res Public Health. 2020;17(7). doi: 10.3390/ijerph17072325. [PubMed: 32235594]. [PubMed Central: PMC7177215].

15. Vaccarella S, Lortet-Tieulent J, Saracci R, Fidler MM, Conway DI, Vilahur $\mathrm{N}$, et al. Reducing social inequalities in cancer: Setting priorities for research. CA Cancer J Clin. 2018;68(5):324-6. doi: 10.3322/caac.21463. [PubMed: 30152865].

16. Danaei G, Farzadfar F, Kelishadi R, Rashidian A, Rouhani OM, Ahmadnia S, et al. Iran in transition. Lancet. 2019;393(10184):1984-2005. doi: 10.1016/S0140-6736(18)33197-0. [PubMed: 31043324].

17. Parise CA, Caggiano V. Regional variation in disparities in breast cancer specific mortality due to race/ethnicity, socioeconomic status, and urbanization.J Racial Ethn Health Disparities. 2017;4(4):706-17. doi: 10.1007/s40615-016-0274-4. [PubMed: 27604380].

18. Enayatrad M, Yavari P, Etemad K, Khodakarim S, Mahdavi S. Association of urbanization levels and colorectal cancer incidence in Iran. Int J Cancer Manag. 2018;11(8). e68476. doi:10.5812/ijcm.68476. 
19. Chen W, Zheng R, Zhang S, Zeng H, Zuo T, Xia C, et al. Cancer incidence and mortality in China in 2013: An analysis based on urbanization level. Chin J Cancer Res. 2017;29(1):1-10. doi: 10.21147/j.issn.10009604.2017.01.01. [PubMed: 28373748]. [PubMed Central: PMC5348470].

20. Au D, Syed J, Siddiqui S. Mp69-17 incidence of prostate cancer stratified by county education, poverty, and urbanization levels: A population based analysis of Seer. J Urology. 2017;197(4S). doi: 10.1016/j.juro.2017.02.2313.

21. Momenyan S, Sadeghifar M, Sarvi F, Khodadost M, Mosavi-Jarrahi A, Ghaffari ME, et al. Relationship between urbanization and cancer incidence in iran using quantile regression. Asian Pac J Cancer Prev. 2016;17(S3):113-7. doi: 10.7314/apjcp.2016.17.s3.113. [PubMed: 27165247].

22. Luzzati T, Parenti A, Rughi T. Economic growth and cancer incidence. Ecol Econ. 2018;146:381-96. doi: 10.1016/j.ecolecon.2017.11.031.

23. Fidler MM, Soerjomataram I, Bray F. A global view on cancer incidence and national levels of the human development index. Int J Cancer. 2016;139(11):2436-46. doi: 10.1002/ijc.30382. [PubMed: 27522007].

24. Tan KG, Lim TO, Zhang Y, Tan I. Global liveable and smart Cities Index: Ranking analysis, simulation and policy evaluation. Singapore: World Scientific; 2019. doi: 10.1142/11587.

25. Khorrami Z, Mirzaei M, Fadakar Davarani MM, Khanjani N. Measuring liveability in Iranian cities using the Global Liveable City Index (GLCI). Health Scope. 2021;10(2). e112409. doi:10.5812/jhealthscope.112409.

26. Mohebbi E, Nahvijou A, Hadji M, Rashidian H, Seyyedsalehi MS, Nemati S, et al. Iran Cancer Statistics in 2012 and projection of cancer incidence by 2035. Basic \& Clinical Cancer Research. 2017;9(3):3-22.

27. Drewnowski A, Moudon AV, Jiao J, Aggarwal A, Charreire H, Chaix B. Food environment and socioeconomic status influence obesity rates in Seattle and in Paris. Int J Obes. 2014;38(2):306-14. doi: 10.1038/ijo.2013.97. [PubMed: 23736365]. [PubMed Central: PMC3955164].

28. Neupane S, Bray F, Auvinen A. National economic and development indicators and international variation in prostate cancer incidence and mortality: An ecological analysis. World J Urol. 2017;35(6):851-8. doi: 10.1007/s00345-016-1953-9. [PubMed: 27744614].

29. Wong MC, Jiang JY, Goggins WB, Liang M, Fang Y, Fung FD, et al. International incidence and mortality trends of liver cancer: A global profile. Sci Rep. 2017;7:45846. doi:10.1038/srep45846. [PubMed: 28361988]. [PubMed Central: PMC5374459].

30. Su SY, Liaw YP, Jhuang JR, Hsu SY, Chiang CJ, Yang YW, et al. Associations between ambient air pollution and cancer incidence in Taiwan: An ecological study of geographical variations. BMC Public Health. 2019;19(1):1496. doi: 10.1186/s12889-019-7849-z. [PubMed: 31706295]. [PubMed Central: PMC6842529].
31. Farhood B, Raei B, Malekzadeh R, Shirvani M, Najafi M, Mortezazadeh T. A review of incidence and mortality of colorectal, lung, liver, thyroid, and bladder cancers in Iran and compared to other countries. Contemp Oncol. 2019;23(1):7-15. doi: 10.5114/wo.2019.84112. [PubMed: 31061631]. [PubMed Central: PMC6500388].

32. Prüss-Üstün A, Wolf J, Corvalán C, Bos R, Neira M. Preventing disease through healthy environments: A global assessment of the burden of disease from environmental risks. Geneva, Switzerland: World Health Organization; 2016.

33. Jagai JS, Messer LC, Rappazzo KM, Gray CL, Grabich SC, Lobdell DT County-level cumulative environmental quality associated with cancer incidence. Cancer. 2017;123(15):2901-8. doi: 10.1002/cncr.30709. [PubMed: 28480506]. [PubMed Central: PMC6121813].

34. Wu S, Powers S, Zhu W, Hannun YA. Substantial contribution of extrinsic risk factors to cancer development. Nature. 2016;529(7584):437. doi: 10.1038/nature16166. [PubMed: 26675728]. [PubMed Central: PMC4836858].

35. Savijarvi S, Seppa K, Malila N, Pitkaniemi J, Heikkinen S. Trends of colorectal cancer incidence by education and socioeconomic status in Finland. Acta Oncol. 2019;58(11):1557-63. doi: 10.1080/0284186X.2019.1652340. [PubMed: 31437070].

36. Leufkens AM, Van Duijnhoven FJ, Boshuizen HC, Siersema PD, Kunst $\mathrm{AE}$, Mouw $\mathrm{T}$, et al. Educational level and risk of colorectal cancer in EPIC with specific reference to tumor location. Int J Cancer. 2012;130(3):622-30. doi:10.1002/ijc.26030. [PubMed: 21412763].

37. Dong JY, Qin LQ. Education level and breast cancer incidence: A meta-analysis of cohort studies. Menopause. 2020;27(1):113-8. doi: 10.1097/GME.0000000000001425. [PubMed: 31479033].

38. Lin T, Xue X, Shi L, Gao L. Urban spatial expansion and its impacts on island ecosystem services and landscape pattern: A case study of the island city of Xiamen, Southeast China. Ocean Coast Manag. 2013;81:906. doi: 10.1016/j.ocecoaman.2012.06.014.

39. Mostert S, Njuguna F, Olbara G, Sindano S, Sitaresmi MN, Supriyadi E, et al. Corruption in health-care systems and its effect on cancer care in Africa. Lancet Oncol. 2015;16(8):e394-404. doi: 10.1016/S14702045(15)00163-1. [PubMed: 26248847].

40. Klomp J, De Haan J. Effects of governance on health: A cross-national analysis of 101 countries. Kyklos. 2008;61(4):599-614. doi: 10.1111/j.14676435.2008.00415.x.

41. Samuel S. Medico-legal. Aust J Gen Pract. 2019;48(1-2):5. doi: 10.31128/AJGP-01-19-1234e. [PubMed: 31256454].

42. Alizadeh-Navaei R, Hedayatizadeh-Omran A, Janbabaei G. Cancer incidence pattern in Iran provinces and association with human development index. World J Cancer Res. 2017;4. e913. 